\title{
THE PRESENTATION OF SELF IN SOCIAL NETWORKING SITES: AN INTRODUCTION, THEORY AND THE CURRENT STATE OF THE SCHOLARSHIP
}

\author{
Osman SOLMAZ \\ Dicle Üniversitesi, Türkiye \\ osolmaz@dicle.edu.tr \\ https://orcid.org/0000-0003-2983-1177
}

\begin{abstract}
This study aimed to lay out an up-to-date literature review on self-presentation and impression management (Goffman, 1959) in social networking sites (SNSs) through a descriptive analysis method. Following an introduction to the concepts, and the significance of self-presentation research, the current state of the discourse has been discussed under four themes: the debate of actual versus idealized selves in SNSs, resources for self-presentation in SNSs, online self-presentation typology and strategies, and determinants of online self-presentation. The review indicated that impression management typology was found to be a useful analytical framework for future research. However, it was reported that users employed various self-presentation tactics to create a favorable impression on others as well. It was also revealed that personality traits, technical features of SNSs, audience size and diversity, culture, and other-provided information were among the determinants of self-presentation. Finally, it was shown that self-presentation in SNSs merits focused attention as more research is needed to gain a solid understanding of to what extent actual selves are presented online. The study concluded with a call for further research in the investigation of the presentation of self in educational settings including second language teaching and learning contexts.
\end{abstract}

Keywords: Self-presentation, Impression management, Social Networking Sites

\section{SOSYAL PAYLAŞIM SITELERINDE BENLİĞİN SUNUMU: GİIŞ, TEORI VE ARAŞTIRMALARDAKI GÜNCEL DURUM}

\section{ÖZ}

Bu çalışmada sosyal paylaşım sitelerinde benliğin sunumu ve izlenim yönetimi (Goffman, 1959) üzerine yapılan çalışmalarla ilgili betimsel analiz yöntemiyle güncel bir alanyazın taraması yapılması amaçlanmıştır. İlgili kavramlara genel bir giriş ve benlik sunumu çalışmalarının öneminin ortaya konulmasını takiben literatürdeki mevcut durum dört temel tema altında ele alınmıştır: çevrimiçi benlik sunumunu belirleyen unsurlar, sosyal ağlarda benlik sunumu için kullanılan kaynaklar, çevrimiçi benlik sunumu tipolojisi ve stratejileri, sosyal ağlarda gerçek ve idealize edilmiş benliklerin kıyaslanması. Yapılan inceleme izlenim yönetimi tipolojisinin gelecekte yapılacak çalışmalar için faydalı bir analitik çerçeve olduğuna işaret etmiştir. Bununla birlikte, çalışmalarda kullanıcıların başkaları üzerinde olumlu bir izlenim yaratmak için çeşitli kişisel sunum taktikleri kullandığı bulgusu paylaşılmıştır. Ayrıca, kişilik özellikleri, sosyal paylaşım sitelerinin teknik özellikleri, ağ büyüklüğü ve çeşitliliği, kültür, ve ağdaki diğer bilgilerin benlik sunumunun belirleyicileri arasında olduğu bulunmuştur. Son olarak, gerçek benliklerin dijital ortamda ne derecede sunulduğunu daha iyi anlamak için daha fazla araştırmaya ihtiyaç olduğu için, sosyal paylaşım sitelerinde benlik sunumu konusunun dikkatli bir biçimde araştırılması gerektiği gösterilmiştir. Çalışma aralarında ikinci dil edinimi ve öğretimi alanlarının da olduğu eğitim ortamlarında benlik sunumu konusunda daha fazla araştırma yapılması çağrısıyla sonuçlanmıştır.

Anahtar kelimeler: Benlik Sunumu, Izlenim Yönetimi, Sosyal Paylaşım Siteleri 


\section{INTRODUCTION}

The advent of new forms of computer-mediated-communication (CMC) including the SNS-mediated technologies brought academic attention to the examination of such sites. The mediated nature of these platforms are found to offer a virtual space for individuals to perform who they are (Bouvier, 2012), carefully create an image for themselves (VanBogart, 2013), and craft their digital identities (Chen, 2013; Maghrabi, Oakley, \& Nemati, 2014). The questions raised in this growing body of the research are now centralized around users' management of impressions by means of multimodal cues afforded by social networking sites. This study aims to present the current state of discourse on self-presentation in SNSs along with theoretical and methodological approaches employed and future directions in selfpresentation research.

\section{The Significance of Self-Presentation Research}

Self-presentation is defined as "the process by which people conveys to others that they are a certain kind of person or possess certain characteristics" (Leary, 1996, p. 17) and the term is interchangeably used with 'impression management' across the studies (e.g., Abro \& Zhenfang, 2013; Rosenberg \& Egbert, 2011). The relationship between social networking sites and self-presentation as an area of research is often considered as complex and intertwined. While Tufekci (2008) explained this relationship by regarding self-presentation as a minimum requirement for participation in online social networks, Rosenberg and Egbert (2011) speculated that SNSs were specifically dedicated to forming and managing impressions in addition to maintenance and seeking of relations. Barash, Ducheneaut, Isaacs, and Bellotti's (2010) research showed that "users, now more than ever, need to walk a fine line between the impressions they 'give' and inadvertently 'give off"' (p. 210). In the light of such findings, some studies pay special attention to students' SNS use awareness. To illustrate, Vorvoreanu, Clark, and Boisvenue (2013) argued that there was a need to teach students social media literacy and proposed a plan for online identity management to be integrated into undergraduate curricula. Moreover, Rambe (2013) exhibited how students could be terrified by employers who search SNS presence of potential employees and VanBogart (2013) reported the effects of presented information on individuals' professional credibility.

Examination of online social networking systems is also important because they have the potential to provide insight regarding how people maintain their social networks (Tong, Heide, \& Langwell, 2008) and to what extent they can be compared with traditional social networks and the ways people present themselves in these contexts. Since SNSs offer carefully constructed and controlled management opportunities (Bouvier, 2012), there is a need to understand how traditional self-presentation strategies translate into such systems with relatively larger social networks which often include both private and professional audience.

\section{Theoretical and Methodological Trends across Research on Self-Presentation in SNSs}

Past research investigating identity presentation and impression management on SNSs is often theoretically grounded in the work of sociologist Erving Goffman. A number of other theories including social identity (Farnham \& Churchill, 2011) and social semiotics (Bouvier, 2012) are used alongside with Goffman's work. Furthermore, some studies interpreted their research with both the theory of Impression Management and frameworks particular to their disciplines (e.g. 'Constituency Service' in Jackson \& Lilleker, 2011). However, it is clear that Goffman's Impression Management is the most common theoretical framework used in the interpretation of identity presentations on SNSs.

In his book, The Presentation of Self in Everyday Life, Goffman (1959) used a now well-known metaphor of stage and audience, and described people displaying various roles on the stage of life as actors and how they consciously or subconsciously present different identity performances to different audiences in order to make specific impressions. Self-presentation while interacting with others are realized through expressions given, which are direct, verbal, and controlled, and expressions given off, 
which are subtle, non-verbal, contextual and unconscious (Cho, 2010). Thus, people may both develop strategic actions and display unintentional performances which make the audience form an impression.

The literature clearly indicated that SNSs offered multimodal tools for individuals to present themselves through verbal and non-verbal communication in online settings (e.g., Solmaz, 2015; Young, 2013). By going beyond the empirical findings of SNSs as a potential means for self-presentation, Krämer and Haferkamp (2011) noted that people were highly motivated to use SNSs to present themselves, while a number of scholars including Mehdizadeh (2010) listed impression management among the main functions of SNSs. Users can indeed manage the impressions they create by highlighting or minimizing certain aspects of their identities. The purposeful choices of language discourse in status updates and comment sections, shared photographs and links in SNSs also reflect the agency of the users. The activities through such textual and visual cues can be interpreted as 'performance' in Goffman's (1959) terminology and the expressions given and given off in offline contexts are transmitted through these cues in SNS platforms. The development in social technologies allows users to form and maintain impressions via not only self-generated cues but also other-provided information (OPI) (Lee \& Lim, 2014; Walther, Heide, Hamel, \& Shulman, 2009). The role of OPI such as comments left by others, the social network of a person itself, and even physical attractiveness of the 'friends' in SNSs on the selfpresentation of an individual started to receive attention from social media experts. In addition to this specific aspect of impression management in SNSs, the type of tools and how they are used in SNS, self-presentation strategies and tactics employed by users, determinants of self-presentation, and the other factors affecting the management and maintenance of individuals' impressions are among the explored areas of research in this context.

The analysis of the previous research also revealed information regarding the methodologies adopted in self-presentation studies in social networking settings. It was observed in the literature that both qualitative and quantitative methods were employed. Data were often collected through semi-structured (Young, 2013) and in-depth interviews (Hilsen \& Helvik, 2014), surveys and questionnaires (Lee, 2014; Michikyan, Dennis, \& Subrahmanyam, 2014), custom-built Facebook application (Barash et al, 2010), social network analysis (Solmaz, 2015), and video-recording tools (Paslanmaz \& Narmanlıŏlu, 2019). Data were usually analyzed and interpreted by means of discourse analysis (Bouvier, 2012), thematic analysis (Rambe, 2013), and other methodological preferences depending on the nature of the research design. For instance, in addition to semi-structured interviews, Young (2013) used verbal protocols in which the participants viewed their SNS profile and talked aloud about its content, while Rambe's (2013) design was exploratory and the topic gradually narrowed as the research progressed. Overall, it can be concluded that there is a diversity of employed methodologies across the studies conducted in this area.

\section{The Present Study}

This study aimed to provide a broad view of the research conducted with respect to self-presentation in social networking sites. For this purpose, the selection criteria for the literature review were devised as the following; a) SNSs consisted of mainstream social networks of Facebook, Twitter, and Instagram, b) studies included were published in the peer-reviewed and indexed journals in the last ten years. In line with the criteria, a systematic search of the related studies was conducted in major databases, including Science Direct, Web of Science, Google Scholar, ERIC, and DOAJ by using the following keywords: "self-presentation", "presentation of the self", "impression management", "online selfpresentation", "online impression management". The words and word groups of "social networking sites", "Facebook", "Twitter", and "Instagram" were also used to reach target studies in a more effective way. Following the collection of the works, key themes emerging from the content analysis of previous research were synthesized to illuminate a broad perspective on the prior research.

\section{EMERGING THEMES}

The analysis revealed four major themes across the investigated area of research on the presentation of self in social networking sites. These major themes, some of which were formed through two subcategories, consisted of the following: 
- Determinants of Online Self-Presentation

- Resources for Self-Presentation in SNSs

- Online Self-Presentation Typology and Strategies

- Actual vs. Idealized Selves in Social Networking Sites

\section{Determinants of Online Self-Presentation}

Self-presentation behaviors in SNSs are affected by several factors which are mainly categorized as internal factors such as personality/individual differences and external factors including audience diversity and size (Jackson \& Ruchner, 2018; Rui \& Stefanone, 2013). The review of self-presentation literature revealed that individual differences, the SNSs themselves, culture, audience size and diversity affected the process of individuals portraying themselves in SNSs. The psychosocial variables, for example, were demonstrated to have relationship with impression management. While Mehdizadeh (2014) found that college students with high degree of narcissism and low self-esteem promoted themselves more, Michikyan et al. (2014) showed that emerging adults with lower self-esteem and less coherent sense of the self, presented their false self on SNS comparatively more. Rosenberg and Egbert (2011) investigated the role of personal traits on impression management and found that high affinityseekers, those with a strong desire to be liked by others, were more likely to achieve their goals thanks to the positively seen role-modeling tactics. Conducting a research on one hundred and eighty four undergraduates, Seidman (2013) found a positive connection between agreeableness, neuroticism, extraversion and the tendency to express one's actual self. Finally, investigating the self-presentation of university-level students in the context of Turkey, Çakmak (2018) found a relationship between narcissism and individuals' online self-presentation practices.

Audience size and diversity are considered as two other important determinants of online selfpresentation. It was found that audience size could prove to be a significant cue for others to make social judgments about an individual (Tong et al., 2008), regardless of the audience being imaginary or perceived as real (Hogan, 2010). Rui and Stefanone (2013) hypothesized that larger social networks required more self-disclosure and active impression management as sociological theories supported that self-disclosure could facilitate relationship development and assist with maintenance of networks. In line with their hypothesis, they found that audience size had a positive relationship with adoption of protective strategies in order to deal with unwanted other-generated information. Examining Facebook users' self-presentation of political views, Hayes, Smock and Carr (2015) found that a higher size of network had an impact on increasing engagement in disclosure behaviors. In a similar vein, Gil-Lopez et al. (2018) reported that the size and heterogeneity of individuals' audiences positively affected the quantity of their disclosures.

Audience diversity was also reported to be significant in self-presentation studies since users typically merge audiences from different social networks and often have to manage their impression to an audience with multiple characteristics. Cho (2010) expressed that the perceived target audience was more important compared to actual audience since behaviors were mostly based on the perception of audience. Other works (e.g., Ranzini \& Hoek, 2017; Yau \& Reich, 2018) work provided additional support to the idea that imaginary audiences of Facebook users influence individuals' impression management. In Bouvier's (2012) research, however, participants did not take audience diversity into account in their self-presentations. Prior research also showed that the presence of peers among existing or imaginary networks affected teenagers' impression management strategies by causing them to compare themselves with their peers (Chua \& Chang, 2016). On the other hand, when young adults receive a positive support from their network; they were found to be less reserved with respect to their online self-presentation (Yang \& Brown, 2016). Overall, audience diversity has the potential to complicate impression management as different audience segments may not have same expectations about an individual's presentation.

Other-provided information (OPI) and culture were emphasized in the literature as well. While Walther et al. (2009) found that comments of friends were more effective than user's explicit presentations, it was demonstrated that commenter's age (Lee \& Lim, 2014) and physical attractiveness of user's friends (Tong et al., 2008) was utilized in the formation of an impression. OPI is one of the underexplored areas 
of online self-presentation and it is important as OPI may not be consistent with the crafted image presented by an individual especially if they are to pursuit an idealized self (Rui \& Stefanone, 2013). Similarly, culture is considered to have 'major influence' on self-presentation and a distinction between individualistic (e.g., Western) vs. collectivist (e.g., East Asian) cultures are often made in the literature (Zhao \& Jiang, 2011). It is reported that cultural norms in offline contexts are reflected in the ways users present themselves online and Americans were found to disclose themselves more by means of status updates compared to Singaporeans (Rui \& Stefanone, 2013). Similarly, findings indicated that selfpresentation was sensitive to national culture and Chinese disclosed themselves less than Americans (Zhao \& Jiang, 2011). However, the same study found that Americans tended to share profile photos with others and this contradicted with the 'Western individualism' and 'Eastern collectivism' theory. Overall, there is a need for further research for a better understanding of the factors affecting selfpresentation in social networks.

\section{Resources for Self-Presentation in SNSS}

The discourse on the self-presentation in SNSs is partly focused on the new media from which individuals benefit to manage their impressions and how they perform in these contexts. SNSs indeed offer multimodal resources of 'impression-enabling cues' which include self-generated resources (e.g., status updates), other-generated cues (e.g., comments of others), cues about the cues (e.g., profile photos of commenters) (Lee \& Lim, 2014; Solmaz, 2015) and machine-generated statements (e.g., "Person X liked this"). Analyzing 63 Facebook accounts, Zhao, Grasmuck, and Martin (2008) presented a continuum of expressions given and given off which are interpreted as implicit and explicit identity claims. In addition to such studies with broader perspectives, research also focused on profiles and profile images on SNSs (Zhao \& Jiang, 2011), photographs (Huang \& Park, 2013), status updates (Jung et al., 2012), 'About me' section of SNSs (Zhao et al, 2008), joining groups and pages (Young, 2013), technical customization of SNS elements (Solmaz, 2015) and impression-enabling cues about cues (Lee \& Lim, 2014).

Being an important element on SNSs, 'About Me' section is arguably the most explicit resource for selfpresentation as users can display personal information such as gender, age, relationship/ marital status, ethnicity, interests, education, occupation, and sexual orientation. This has been referred as a 'classic' form of engagement in impression management on SNSs (Krämer \& Haferkamp, 2011), which often includes a space where members can narrate self-description by introducing themselves to their audiences. However, Zhao et al. (2008) found that some of the participants in their study did not have 'about me' blurb in Facebook accounts and those who had it wrote just one or two short sentences. Compared to 'About me' section, profiles offer spaces to exhibit expressions given off as well thanks to its multimodal-rich environment. While creating an online profile, users can take the control of how they portray themselves and want to impress others by means of imagery, language, and media. Zhao and Jiang (2011) stated that profile photos could be regarded as a form of implicit identity formation, which provides an opportunity for users to show themselves.

Photographs, which are among nonverbal cues exploited in SNSs, are among the important resources of identity construction and performance online. Individuals deliberately choose to give off a desired impression to others in their social networks (VanBogart, 2013). International graduate students, for example, described the role of photographs in helping them display who they were and with whom they were affiliated (Solmaz, 2015). Zhao and Jiang (2011) reported from early works that gender and age affected the photos people choose for their profiles. In a similar vein, participants of Young's (2013) study agreed that individuals would choose a profile image which displayed them in the best light settings. The cues about cues such as the physical attractiveness of one's friends on Facebook wall postings was also found to effect the profile owner's physical attractiveness significantly (Walther et al., 2009). Apart from the creation of a visual identity, photos were also used as a way to highlight social relationship and connection with others (e.g., displaying another person on the photo), to subtly demonstrate social acceptability, and to receive comments from social networks (Young, 2013). In the case of Instagram, it was noted that temporary stories featuring videos, boomerangs, photos and GIFs 
were adopted by social media influencers as elements of self-presentation in the majority of temporary stories (Paslanmaz \& Narmanlıoğlu, 2019).

Status updates, joining groups and "liking" pages are other verbal and nonverbal cues that were investigated in the literature although published research data is scarce. In one of the leading studies, Barash et al. (2010) found that entertaining status posts resulted in positive communication in a social networking indicating a successful impression management, while both Barash et al. (2010) and Young (2013) noted that people who continually posted negative and/or mundane updates were seen critically. In South Korean context, Jung et al. (2012) revealed that impression management was among the motivating factors for individuals to post and read such messages. Similarly, Young (2013) demonstrated that joining groups and pages also played a role in presentation of self in SNSs: "... reviewing a person's choices of Facebook group membership can provide insights into facets of their identity", and warned, "Although these interpretations may be very misleading if a person has not been selective or purposeful in joining online groups" (p. 11). The role of status updates and activities such as joining groups and "liking" pages and how they affect the impression management of users need to be further examined in detail.

\section{Online Self-Presentation Typology and Strategies}

As he was mostly interested in the theoretical aspects of the concepts of self-presentation and impression management, Erving Goffman shared neither a taxonomy nor typology of self-presentation, nor impression management tactics people use (Barash et al., 2010). A commonly used typology for understanding impression management was provided by Jones and Pittman (1982) who argued that people exhibit one or more of the following behaviors when they want to influence the perception of others: Ingratiation, Self-promotion, Supplication, Exemplification, Intimidation (Jackson \& Lilleker, 2011). This kind of typology can prove useful if it is used as analytical framework in the interpretation of verbal cues in self-presentation in SNS research.

A separate thread of research is on the examination of self-presentation strategies/tactics employed by SNS users, who want to convince their audience that they are the particular type of person they image themselves (Leary, 1996). The impression management typology discussed above was also employed as self-presentation strategies. For instance, VanBogart (2013) found that ingratiation (i.e. the goal of being liked) and competence/self-promotion (i.e. the goal of being perceived as qualified) were the most commonly used self-presentation tactics. Jung et al. (2012) maintained that reading activities on SNSs (e.g., reading what and how others think and reply) helped users tailor their impressions to other people in order to get the validation of their crafted identity. Rui and Stefanone (2013) noted that users could employ protective strategies such as choosing private communication channels and blocking certain network members from viewing some content or limiting self-disclosures to neutral updates. This type of strategies could include tactics for managing other people's unwanted posts and unwanted photo tagging (see Birnholtz, 2017). Carefully selecting Facebook friends and changing the spelling of one's name (Vorvoreanu et al., 2013), censoring of personal material and use of available privacy controls (Young, 2013), producing elaborate support-seeking messages through putting more effort into post compositions (Oh \& LaRose, 2017) are listed among the other self-presentation strategies by individuals. Finally, some individuals are also likely to develop their own tactics similar to one of Rambe's (2013) participants' criterion for 'putting stuff on Facebook': "If I wouldn't be embarrassed to tell my mother, I will put it on Facebook" (p. 325). Finally, Chua and Chang's (2016) research revealed that meanings attributed to some elements of social media such as likes and followers constituted an important part of maintaining a digital self-presentation.

\section{Actual vs. Idealized Selves in Social Networking Sites}

A major debate in the research of self-presentation in SNSs is about whether online self-presentation is an idealized version of individuals' selves or a virtual extension of images drawn in real life contexts. Given that SNSs are deeply penetrated in the lives of many users and intertwined with the daily routine, the distinction between online and offline identities are not easy to investigate and interpret (Bouvier, 
2012). Back et al. (2010) reported two major hypotheses that are discussed in this particular subject. Idealized virtual-identity hypothesis (IVIH) predicts that self-presentation in online social networks do not reflect actual characteristics, whereas extended real-life hypothesis (ERLH) argues that features displayed on SNSs are part of actual personality of users (Back et al., 2010). Testing these hypotheses, Back et al. (2010) found evidence of real life elements and no self-idealization. There were a number of other studies supporting the ERLH as well. Hilsen and Helvik (2014) showed that both young and mature adults in their study presented themselves in a fairly open and 'non-manipulative' way although "Still, being yourself on Facebook means different thing to different people" (p. 9). In a similar vein, DiMicco and Millen (2007) noted that online profiles or behaviors of the majority of the users were not manipulated. Among the reasons for the results to be in favor of ERLH could be that Facebook required authentic representation (Young, 2013), there were real consequences of the created identities on Facebook (Zhao et al., 2008), and audiences of users corresponded to real-life audience.

In some studies such as Kaskazi (2014), participants did not think that their Facebook profile mirrored their identity, although they believed that Twitter was a better mirror as they felt more comfortable to express themselves there. Bouvier (2012) found that identity performances online were more reflexive as there was more time to work on them and SNSs were used to create an idealized version of individuals themselves. Similarly, Michikyan et al. (2014) reported that self-presentations online might not represent offline identities as users can control their online behaviors and personality differences might affect presenting multiple facets of the self. Apart from studies supporting $I V I H$, there are researchers taking a balanced approach to both sides. Farnham and Churchill (2011) mentioned that lives of people had facets and different social situations necessitated different facets to be presented. Zhao et al. (2008) also pointed out that identity was a social product and characteristics of the environment lead individuals to situate themselves better. Thus, "'True selves', 'real selves', and 'hoped-for possible selves' are products of different situations rather than characteristics of different individuals" (p. 1831). Overall, as illustrated in previous research (e.g., Chua \& Chang, 2016), social media affects the dynamics and intensity of impression management practices online although major characteristics of one's presentation of self remains similar.

Prior research has investigated the differences between self-presentation in online and offline contexts in the larger context of online identity construction as well. According to boyd (2007), there are four aspects of self-presentation in SNSs which are different from traditional identity constructions: persistence (storage of electronic text), searchability, replicability (duplicating/changing what one has created), and invisible audiences. Multiple and invisible audiences, for example, do not allow users to present specific information with a particular audience especially when employing profile resources of SNSs. On the other hand, individuals can present themselves to a selected and perceptible audience in face-to-face encounters through adapting themselves for different interactions (Krämer \& Haferkamp, 2011). Apart from these differences, online self-presentation lacks nonverbal cues such as facial expressions and body gestures which can be used in real life situations, while majority of multimodal tools present in SNSs are under the control of users in online contexts. The control over the elements creates opportunities for users to modify, edit, or remove the content about self (Jung et al., 2012), thus leading to a sense of more effective impression management. Moreover, other-provided information (e.g., comments of others in an individual's network) can be difficult to anticipate and affect user's presentation "in front of" an invisible audience. Furthermore, As also reported in Krämer and Haferkamp's (2011) comparison between self-presentation offline and online across SNSs, idealized selves in online contexts might face criticism by profile owner's face-to-face contacts who are also present among the online audience while it may be more typically in line with such contacts' expectations in face-to-face encounters. This is partly because the profile owner is partly forced to address a broad audience, thus being unable to provide relevant information to different groups among the audience (Krämer \& Haferkamp, 2011). The overall review of the literature reveals that a solid understanding of offline self-presentation and further research on self-presentation in SNSs would illustrate a broad perspective on the nature of SNS users' online self-presentation and its correspondence to their real lives. 


\section{CONCLUSION}

This paper aimed to lay out an up-to-date literature review on self-presentation and impression management (Goffman, 1959) in social networking sites. Following an introduction to the concepts, the study demonstrated why self-presentation on SNSs merits attention and what kind of methodologies was employed in previous research. The current state of the discourse has been discussed under five themes: a comparison of offline and online self-presentation, resources for self-presentation in SNSs, online selfpresentation typology and strategies, determinants of online self-presentation, and the debate of actual versus idealized selves in SNSs. The review indicated that there were differences between real life and online presentation of individuals, and therefore, self-presentation in digital contexts, particularly in SNS, needs to be addressed as a separate thread of investigation. Among the findings were the reports which indicated that SNS users adopted various self-presentation tactics to create a favorable impression on others. The analysis of another theme revealed that there were several determinants of selfpresentation including personality traits, technical features of SNSs, audience size and diversity in the network, culture, and other-provided information. It was also shown that more research is needed to gain a solid understanding of to what extent real selves are presented online and impression management typology might be one of the useful analytical lenses for such research.

Although various studies are conducted in the field of education, there is a clear lack of research on selfpresentation in second language teaching and learning (L2TL) contexts. L2TL experts need to analyze how L2 learners present themselves and what strategies they use for different purposes (e.g., Solmaz, 2015). Broadly speaking, the effect of SNS-generated statements on users and whether it shapes their social judgments of others should be carefully examined. Similarly, the relationship between textual and multimodal cues and to what extent they influence users' impression formation processes need to be empirically addressed in educational context. Since the majority of self-presentation research is concentrated on Facebook, analysis of other SNSs such as Twitter and Instagram, and how the findings given above carry onto them should be investigated. Overall, the self-presentation in SNSs and what kind of real consequences they might have need to be further analyzed especially in educational contexts. Overall, it can be concluded from the review of the literature that self-presentation in SNSs is a significant area of research across various disciplines, which have been discussed from a multitude of perspectives.

\section{REFERENCES}

Abro, M., \& Zhenfang, L. (2013). Influence of Self-presentation on Bridging Social Capital in SNSs: A Moderating Effect of Self-presentation. Research on Humanities and Social Sciences, 3(19), 74-81.

Back, M.D., Stopfer, J. M., Vazire, S., Gaddis, S., Schmukle, S. C., Egloff, B., \& Gosling, S. D. (2010). Facebook Profiles Reflect Actual Personality, Not Self-Idealization. Psychological Science, 21(3), 372374.

Barash, V., Duchenaut, N., Isaacs, E. \& Bellotti, V. (2010). Faceplant: Impression (mis)management in Facebook status updates. Proceedings from ICWSM 2010.

Bouvier, G. (2012). How Facebook users select identity categories for self-presentation. Journal of Multicultural Discourses, 7(1), 37-57

boyd, D. (2007). Why youth social network sites: The role of networked publics in teenage social life. Youth, identity and digital media, D. Buckingham (ed.), 119-42. Cambridge: The MIT Press. http://www.mitpressjournals.org/toc/dmal/-/6

Chen, H. (2013). Identity practices of multilingual writers in social networking spaces. Language Learning \& Technology, 17(2), 143-170.

Cho, S. E. (2010). Cross-cultural comparison of Korean and American Social Network Sites: Exploring Cultural Differences in Social Relationships and Self-Presentation. Unpublished doctoral dissertation. New Jersey: The State University of New Jersey

Research Article - Submit Date: 16.08.2020, Acceptance Date: 14.09.2020 DOI NO: 10.17932/IAU.EJNM.25480200.2021/ejnm_v5i1005

Copyright $(\mathcal{C}$ e-Journal of New Media 
Chua, T. H. H., \& Chang, L. (2016). Follow me and like my beautiful selfies: Singapore teenage girls' engagement in self-presentation and peer comparison on social media. Computers in Human Behavior, $55,190-197$.

Çakmak, V. (2018). Online Benlik Sunumu ve Narsisizm Arasındaki İlişki: Üniversite Öğrencileri Üzerinde Bir Araştırma. AJIT-e: Online Academic Journal of Information Technology, 9(30), 137-152.

DiMicco, J., \& Millen, D. (2007) Identity management: Multiple presentations of self in Facebook. GROUP'07, November 2007, Sanibel Island, Florida, FL, USA.

Farnham, S. D. \& Churchill, E. F. (2011). Faceted Identity, Faceted Lives: Social and Technical Issues with Being Yourself Online. Proceedings of the ACMC 2011 conference on Computer supported cooperative work, 359-368.

Gil-Lopez, T., Shen, C., Benefield, G. A., Palomares, N. A., Kosinski, M., \& Stillwell, D. (2018). One size fits all: Context collapse, self-presentation strategies and language styles on Facebook. Journal of Computer-Mediated Communication, 23(3), 127-145.

Goffman, E. (1959). The presentation of self in everyday life. Garden City, NY: Doubleday.

Hayes, R. A., Smock, A., \& Carr, C. T. (2015). Face [book] management: Self-presentation of political views on social media. Communication Studies, 66(5), 549-568.

Hilsen, A. I., \& Helvik, T. (2014). The construction of self in social medias, such as Facebook. AI \& Society 2014, 29(1), 3-10.

Hogan, B. (2010). The presentation of self in the age of social media: Distinguishing performances and exhibitions online. Bulletin of Science, Technology \& Society, 30(6), 377-386.

Huang, C., \& Park, D. (2013). Cultural influences on Facebook photographs. International Journal of Psychology, 48(3), 334-343.

Jackson, N. \& Lilleker, D. (2011). Microblogging, Constituency, Service and Impression Management: UK MPs and the Use of Twitter. The Journal of Legislative Studies, 17(1), 86-105.

Jackson, C. A., \& Luchner, A. F. (2018). Self-presentation mediates the relationship between selfcriticism and emotional response to Instagram feedback. Personality and Individual Differences, 133, $1-6$.

Jones, E. and Pittman, T., 1982. Toward a General Theory of Strategic Self-presentation. In J. Suls, (ed.), Psychological Perspective on Self. Hillsdale, NJ: Erlbaum, 231-262.

Jung, Y., Song, H., \& Vorderer, P. (2012). Why do people post and read personal messages in public? The motivation of using personal blogs and its effects on users' loneliness, belonging, and well-being. Computers in Human Behavior, 28, 1626-1633.

Kaskazi, A. (2014). Social Network Identity: Facebook, Twitter and Identity Negotiation Theory. iConference 2014 Proceedings, 858-859.

Krämer, N. C., \& Haferkamp, N. (2011). Online Self-Presentation: Balancing Privacy Concerns and Impression Construction on Social Networking Sites. In S. Trepte \& L. Reinecke (Eds.), Privacy Online: Perspectives on Privacy and Self-Disclosure in the Social Web (pp. 127-141). Berlin: SpringerVerlag.Leary, 1996

Leary, M.R. (1996). Self-presentation: Impression management and interpersonal behavior. Boulder, CO: Westview Press.

Lee, S. Y. (2014). How do people compare themselves with others on social network sites?: The case of Facebook. Computers in Human Behavior, 32, 253-260.

Lee, J., \& Lim, Y. (2014). Who Says What About Whom? Young Voters' Impression Formation of Political Candidates on Social Networking Sites. Mass Communication and Society, 0, 1-20. 
Maghrabi, R. O., Oakley, R. L., \& Nemati, H. R. (2014). The impact of self-selected identity on productive or perverse social capital in social network sites. Computers in Human Behavior, 33, $367-$ 371.

Mehdizadeh, S. (2010). Self-presentation 2.0: Narcissism and self-esteem on Facebook. Cyberpsychology, Behavior, and Social Networking, 13(4), 357-364.

Michikyan, M., Dennis, J., \& Subrahmanyam, K. (2014). Can you guess who I am? Real, Ideal, and False Self-Presentation on Facebook Among Emerging Adults. Emerging Adulthood, 1-10.

Oh, H. J., \& LaRose, R. (2016). Impression management concerns and support-seeking behavior on social network sites. Computers in Human Behavior, 57, 38-47.

Paslanmaz, İ., \& Narmanlıŏlu, H. (2019). Instagram Hikayelerinde Benliğin Sunumu: Influencer'lar Üzerine Bir Araştırma. AJIT-e: Online Academic Journal of Information Technology, 10(39), 24-63.

Rambe, P. (2013). Converged social media: Identity management and engagement on Facebook mobile and blogs. Australasian Journal of Educational Technology, 29(3), 315-336.

Ranzini, G, \& Hoek, E. (2017). To you who (I think) are listening: Imaginary audience and impression management on Facebook. Computers in Human Behavior, 75, 228-235.

Rosenberg, J., \& Egbert, N. (2011). Online impression management: personality traits and concerns for secondary goals as predictors of self-presentation tactics on Facebook. Journal Of Computer-Mediated Communication, 17(1), 1-18.

Rui, J., \& Stefanone, M. A. (2013). Strategic self-presentation online: A cross-cultural study. Computers in Human Behavior, 29, 110-118.

Seidman, G. (2013). Self-presentation and belonging on Facebook: How personality influences social media use and motivations. Personality and Individual Differences, 54, 402-407.

Solmaz, O. (2015). Multilingual students' management of transnational identities in online participatory spaces (Unpublished doctoral dissertation). University of Arizona, Arizona.

Tong, S., T., Heide, B. V. D., \& Langwell, L. (2008). Too Much of a Good Thing? The Relationship Between Number of Friends and Interpersonal Impressions on Facebook. Journal of ComputerMediated Communication, 13, 531-549.

Tufekci, Z. (2008). Can you see me now? Audience and disclosure regulation in online social network sites. Bulletin of Science, Technology, and Society, 28(1), 20-36.

VanBogart, S. M. (2013). Establishing Credibility Online Through Impression Management. Unpublished Masters Thesis. Gonzaga University

Vorvoreanu, M., Clark, Q. M., \& Boisvenue, G. A. (2013). Online Identity Management Literacy for Engineering and Technology Students. Journal of Online Engineering Education, 3(1).

Walther, J.B., Heide, B. V. D., Kim, S., Westerman, D., \& Tong, S. T. (2008). The Role of Friends' Appearance and Behavior on Evaluations of Individuals on Facebook: Are We Known by the Company We Keep?. Human Communication Research, 34, 28-49.

Yang, C. C., \& Brown, B. B. (2016). Online self-presentation on Facebook and self development during the college transition. Journal of youth and adolescence, 45(2), 402-416.

Yau, J. C., \& Reich, S. M. (2019). "It's Just a Lot of Work”: Adolescents' Self-Presentation Norms and Practices on Facebook and Instagram. Journal of Research on Adolescence, 29(1), 196-209.

Young, K. (2013). Managing online identity and diverse social networks on Facebook. Webology, 10(2), $1-18$.

Zhao, C., \& Jiang, G. (2011). Cultural Differences on Visual Self-Presentation through Social Networking Site Profile Images. CHI 2011, Vancouver, Canada. 
Zhao, S., Grasmuck, S., \& Martin, J. (2008). Identity construction on Facebook: Digital empowerment in anchored relationships. Computers in Human Behavior, 24, 1816-1836. 